\title{
Reliability Assessment of an Electronic System: A Case Study of a SAGEM-922 Mobile Phone Charger
}

\author{
Akinsanmi Olaitan \\ Federal University Oye-Ekiti \\ Department of Electrical \& \\ Electronics Engineering
}

\author{
Gerald Kelechi ljemaru \\ Federal University Oye-Ekiti \\ Department of Electrical \& \\ Electronics Engineering
}

\author{
Kehinde Oluwafemi \\ Olusuyi \\ Federal University Oye-Ekiti \\ Department of Electrical \& \\ Electronics Engineering
}

\begin{abstract}
The paper assesses the reliability of a Sagem-922 mobile phone charger in Nigeria. The Part Stress method was used to assess the reliability of the system. Data on the failure rate of the various components used in the system were used, with special consideration given to factors such as environment of uses, quality of power supply and service personnel. A comparative assessment was made on the reliability of the charger when operated within the Nigerian environment and when operated within the environment for which it was designed (China). The result shows that lower reliability level is associated with the use of the Sagem-922 chargers in Nigeria, as compared with the reliability level when in use in the country for which it was designed.
\end{abstract}

\section{General Terms}

Uninterruptible Power Supply, Reliability of an Electronic System.

\section{Keywords}

Reliability, Mobile-Phone, Charger, Failure Rate

\section{INTRODUCTION}

Sagem-922 mobile phone charger is a device, which is designed to produce a well regulated voltage for charging the rechargeable battery of the Sagem-922 model of the mobile handset. The reliability of this system, which has an original environment for which it was designed, becomes necessary to determine the degree to which it could be relied upon in the applied environment- Nigeria.

\subsection{Reliability}

Reliability is defined as the probability that a system would perform required function under given conditions for a stated period of time, usually a thousand hours or a million hours. This requires the understanding of probability and statistical concepts, and has, therefore, been found to be a very important tool in forecasting the pattern of failure for systems and hence, the reliability assessment of the systems at hand [3].

\subsection{Part Stress Method}

This is one of two methods used in assessing the reliability of an electronic equipment. In the part stress method, the effects of the various stresses on the actual hardware are put into consideration, with the environmental factor and the quality of the utility. The part count method (the other method) of assessing the reliability of systems is based on the number of different parts, quality level and application environment. The aim in both cases is to determine the failure for a given system operating in a specific environment. However, the part stress method is the better method for assessing the reliability of an existing system, based on the possibilities of considering various stresses peculiar to the equipment in a specific area of application [2] and as such could be relied upon to assess the reliability of the Sagem-922 charger.

\subsection{The Charger System}

The charger system is made of 4 diodes (IN4007) which are used to achieve a full wave rectification, that is, to rectify the voltage from $230 \mathrm{Vac}$ to $230 \mathrm{Vdc}$. The $230 \mathrm{Vdc}$ powers the transistor and in turn delivers the voltage to the input terminal of a chopper transformer which steps down the voltage to $9 \mathrm{Vac}$. The obtained $9 \mathrm{Vac}$ is rectified, filtered and regulated to obtain a maximum voltage of $13 \mathrm{Vdc}$ at the output of the charger. A Light Emitting Diode (LED) is connected across the load to indicate when the charger is working. Fig 1 shows the complete circuit diagram of the system.

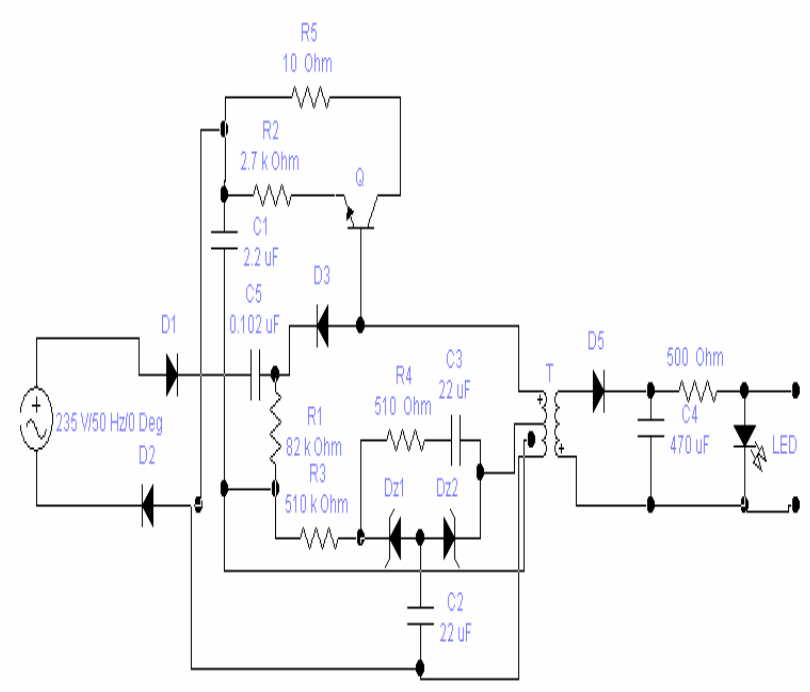

Fig. 1: Circuit diagram of Sagem 922 mobile phone charger (www.sagem.com)

\subsection{Developing Countries}

There are three infrastructural indices of development. These are adequate, reliable and always available energy supply, communication and transportation systems. Any society that has got these three indices is generally characterized as developed society. Such societies include U.S.A., UK, Russia, Canada, France, Italy, Germany and Japan-popularly called the group of eight. There are other countries of the world which are trying to attain this standard, especially other European countries and China among others. Countries which have not attained the three perfect indices above are generally termed developing countries. Examples of such are Nigeria, 
Ghana, Malaysia, and so on. Developing countries are mainly consumers or, at best, assemblers of product designed by developed nations. They inhabit lands with tropical climates in Africa, Asia and Latin America [9]. The electrical power systems of some of these countries are poorly regulated and hence, have fluctuating voltages. Sometimes, in order to meet increased load demand, a deliberate brown out (under voltage condition for a long period of time) capable of introducing voltage stress on voltage sensitive electronic devices are permitted. Some of the regions are periodically subjected to very dry dust (harmattan) which is capable of introducing a high electric field strength of above $4000 \mathrm{~V} / \mathrm{m}$ and sometimes metallic objects moving in this environment accumulate an average of $1000 \mathrm{~V} / \mathrm{m}$ charge e.g. Nigeria [9].

\section{MATERIALS AND METHODS}

It is convenient to specify the reliability of electronic equipment by some probability parameters, which give indication of the failure rate of such a system or equipment, and does not depend on the operating time. By using such parameters, it is also possible to compare the performance between different systems with different operating periods. Two of such parameters that are commonly used are the mean time between failure (MTBF) and mean time to failure (MTTF).

\subsection{Mean Time Between Failure (MTBF)}

Systems users are usually concerned with the length of time that a system will run without failure. This is a measure of the reliability of such a system. For a repairable system, the time before failure is the critical measure, while for non-repairable systems, the time distribution is exponentially decreasing and the (MTBF) is the mean or average time before successful failure of the system. The MTBF can be obtained by running a system for a predetermined length of time under specified conditions. Calculating the average length of time before failures could be seen as an exponentially decreasing function and MTBF is the mean time before consecutive failures. Hence for the failure rate $\lambda$ (the number of failures per unit time), MTBF is given as

$\mathrm{MTBF}=\frac{1}{\lambda}$

For a probability of survival $\mathrm{Pt}$ and for a constant failure rate $\lambda$, the reliability $\mathrm{R}$ is given as

$\mathrm{R}=\mathrm{Pt}=e^{-\lambda \mathrm{t}}$

Where $\mathrm{Pt}=\mathrm{R}$ is the reliability of the system and $\mathrm{t}$ is the specified period of failure free operation and then

$\lambda=\frac{1}{\mathrm{MTBF}}=$ Failure rate

\subsection{Mean Time to Failure (MTTF)}

The mean time to failure MTTF is used for components or items that are not repairable e.g. filament bulbs, resistors, capacitors, diodes and so on, which are disposed of as soon as they fail. This MTTF can be obtained by stressing a large number of components under known conditions for a period of time and noting the number of failures [9].

\subsection{Equipment Failure Profile}

Over the years, complex equipment and components have been found to follow a familiar pattern of failure, which has been well documented. Hazard or failure rates have been calculated for equal time intervals from installation to replacement. When the failure rate is plotted against a time scale spanning the equipment life time, the resulting graph, popularly known as 'bathtub' is obtained as shown in Figure 2 [4].

It exhibits three distinct periods or zones- the infant mortality period, the constant failure rate period and the wear out period. Failure rate is usually expressed in failures per hour (or failures per thousand hours or even per million hours) [6].

\subsection{Infant Mortality Period}

This is the running-in period. During this period, the failure rate has been found to be high, due to other design or manufacturing errors, misuse or misapplication of other identifiable causes. It however falls off rapidly with operation. Failures in this period can be avoided during product development through the use of stimulated tests, or by vigorous stressing during commissioning tests.

\subsection{Constant Failure Rate Period}

This period follows the running-in period. During this period, the failure rate is lowest and is a function of the basic design. Failure results either through accidents or poor operation or maintenance and they can be reduced by good control of operating and maintenance procedures. In this phase, the mean time to failure (MTTF) is the reciprocal of the (constant) failure rate.

\subsection{Wear Out Period}

This period manifests towards the tail end of the equipment/component life. During this period, failure is due to old age; various components are worn out, metals become embrittled, insulation dries out and so on. Failure rates can only be reduced by preventive replacement of these components. Generally in some systems, one or two of the phases (usually the early failures and wear out failures) could be more reduced or effectively absent. Therefore, estimates for the parameters that affect the equipment failure profile of the constituent components, especially the length of the constant failure rate period and the associated failure rates, are essential ingredients for predicting the reliability [5].

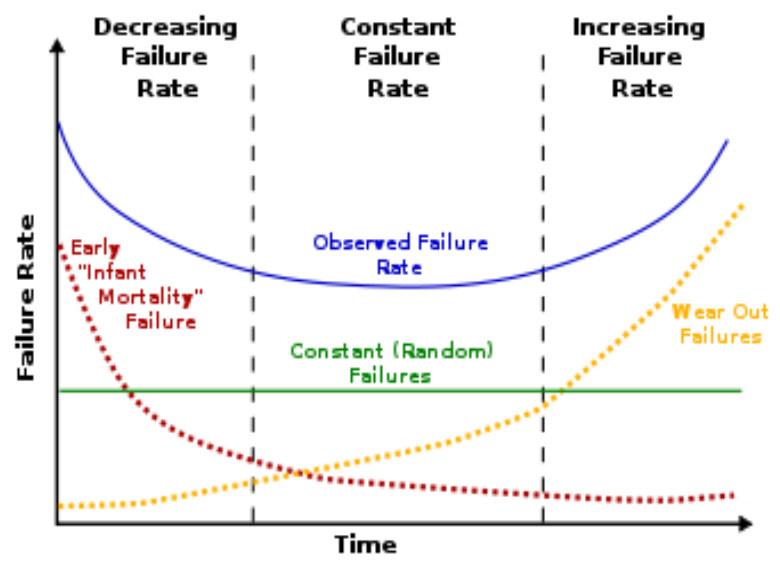

Figure 2 :Equipment Failure Profile Bathtub Curve

\subsection{Equipment Availability}

Equipment availability is the probability that an equipment will perform its required function at a stated instant of time or over a stated period of time. Availability is a function of the utilization factor $(\mathrm{U})$. The utilization factor of a unit or system is defined as the ratio of the operating time $\left(t_{o p}\right)$ to the sum of the maintenance time $t_{m}$, idle time $\left(t_{i d}\right)$ which may occur 
between completion of maintenance and use due to administrative reasons, and the operating time. Mathematically, the utilization factor $\mathrm{U}$, can be expressed as [3].

$\mathrm{U}=\frac{\mathrm{t}_{o p}}{\mathrm{t}_{m}+\mathrm{t}_{i d}+\mathrm{t}_{o p}}$

If the idle time is equal to zero and the maintenance time becomes as small as possible, then utilization factor will approach its maximum value and can now be called availability of a unit or system. Mathematically, this can be expressed as

$\mathrm{A}=\mathrm{U}_{\text {max }}=\frac{\mathrm{t}_{o p}}{\mathrm{t}_{o p}+\mathrm{t}_{o p(\min )}}$

However, the mean time before failure $(\mathrm{MTBF})=\mathrm{t}_{\mathrm{op}}$, and the mean time to failure $(\mathrm{MTTF})=\mathrm{t}_{\mathrm{op}}(\mathrm{min})$, then

$\mathrm{A}=\frac{\mathrm{MTBF}}{\mathrm{MTBF}+\mathrm{MTTF}}$

Therefore, if the availability of an equipment is given as 0.9 , it means that the equipment is working satisfactorily for $90 \%$ of the time, and under repair for the remaining 10\% [8].

\subsection{Reliability Assessment of Electronic Equipment}

The general expression for the part stress method of assessing reliability is given as

$\lambda_{i}=\mathrm{n} \lambda_{\mathrm{G}} \pi_{E} \pi_{A} \pi_{Q} \pi_{N}$

Where $\lambda_{i}=$ the failure of the ith part, $\lambda_{\mathrm{G}}=$ the basic failure rate obtained from derated data for each generic part against normalized stress and temperature factors, $\pi_{E}=$ accounts for the environmental factors other than temperature, $\pi_{A}=$ accounts for secondary stresses (e.g. vibrations, shock, etc.), $\pi_{Q}=$ accounts for the degree of manufacturing control, $\pi_{N}=$ accounts for any additional factor that has not been taken care of above, $\mathrm{n}=$ number of particular component.

For the scope of this work, the above expression for the part stress method was reduced to the expression of

$\lambda_{i}=\mathrm{n} \lambda_{\mathrm{B}} \mathrm{TK}$
Equation 2.8 is based on the factors which described the environment under consideration, where $\lambda_{i}=$ the failure of the ith part, $\mathrm{n}=$ number of particular component $\lambda_{\mathrm{B}}=$ Base failure rate obtained from the de-rated data for each generic part against normalized stress and temperature factors, $\mathrm{T}=$ room temperature of the environment, $\mathrm{K}=$ voltage stress ratio

$$
\text { Voltage Stress }=\frac{\text { Measured Voltage }}{\text { Rated Voltage }}
$$

The information to compute equipment failure rates using the above equation is as given by [9] and [7], if the entire equipment is being used in a particular environment. The failure rates of the regions under consideration (Nigeria and China) are summed up to calculate the inherent system reliability. These failures are constant and are best described by the exponential distribution law for the useful operating region. Then reliability of the equipment or device is given as

$\mathrm{R}_{B}(t)=e^{-\lambda \mathrm{B}_{f} \mathrm{t}}$

Where $\lambda \mathrm{B}_{f} t$ is the base failure rate; this expression can be modified to account for change in failure rates due to wide variation of operating voltages and high surge frequencies, so that the real reliability can be expressed as: [1]

$\mathrm{R}(t)=e^{-\lambda \mathrm{B}_{f} \mathrm{t}}$

\section{RELIABILITY ASSESSMENT OF SAGEM-922 CHARGER}

The design criteria presented above will be used to assess Sagem-922 charger in Nigeria and in the country for which it was designed (China). Hence, we shall have designed failure rate, as it will be applicable to the system operating in the environment for which it will be applicable to the systems operating in the Nigerian environment. The conclusions arrived at will be used to assess the reliability of the Sagem922 in the two environments. The components of the Sagem922 charger, with the generic failure rate, which has taken care of the environmental factors and the application stress factor, and the results of the failure rates are as shown in Table 1 .

Table 1. Failure Rate of the Sagem-922 Charger

\begin{tabular}{|c|c|c|c|c|c|c|c|c|c|c|c|c|c|}
\hline $\begin{array}{l}\text { Circ } \\
\text { uit } \\
\text { comp } \\
\text { onent }\end{array}$ & $\begin{array}{l}\text { Component } \\
\text { description }\end{array}$ & $\begin{array}{l}\text { Qt } \\
\mathbf{y} \\
(\mathbf{n} \\
)\end{array}$ & T & & $\begin{array}{l}\text { Measu } \\
\text { red } \\
\text { voltage } \\
\text { (v) }\end{array}$ & $\begin{array}{c}\text { Volta } \\
\text { ge } \\
\text { stress } \\
\text { ratio, } \\
\text { K }\end{array}$ & $\begin{array}{c}K_{\mathrm{BD}} \times 10^{-6} / \\
\mathrm{hrs}\end{array}$ & $\begin{array}{c}\Lambda_{\mathrm{BN}} \times 10^{-6} / \\
\mathrm{hrs}\end{array}$ & $\begin{array}{c}\text { Qual } \\
\text { ity } \\
\text { Fact } \\
\text { or } \\
\Pi_{Q}\end{array}$ & $\begin{array}{c}\boldsymbol{S i n}=\mathrm{n} \boldsymbol{S}_{\mathrm{BN}} \Pi_{\mathrm{Q}} 1 \\
0^{6} \mathrm{hrs}\end{array}$ & $\begin{array}{c}\mathcal{K}_{\mathrm{ID}}=\mathbf{n} \boldsymbol{K}_{\mathrm{BD}} \Pi \\
\mathrm{Q}^{110^{6}} \mathrm{hrs}\end{array}$ & $\begin{array}{c}\kappa_{\mathrm{effN}}=\mathrm{nTk} \boldsymbol{S}_{\mathrm{B} \Omega} 1 \\
0^{6} \mathrm{hrs}\end{array}$ & $\begin{array}{c}\delta_{\mathrm{effD}}=\mathrm{nTk} \delta_{\mathrm{BD}} 10^{6} \\
\operatorname{hrs}\end{array}$ \\
\hline & & & $\mathrm{N}$ & D & & & & & & & & & \\
\hline $\mathrm{C} 1$ & $\begin{array}{l}\text { Ceramic } \\
\text { capacitor }\end{array}$ & 1 & $\begin{array}{l}2 \\
5\end{array}$ & $\begin{array}{l}2 \\
7\end{array}$ & 38 & $\begin{array}{c}0.062 \\
5\end{array}$ & 0.011 & 0.047 & 3 & 0.141 & 0.033 & 4.55 & 1.025 \\
\hline $\mathrm{C} 2$ & $\begin{array}{l}\text { Ceramic } \\
\text { capacitor }\end{array}$ & 1 & $\begin{array}{l}2 \\
5\end{array}$ & $\begin{array}{l}2 \\
7\end{array}$ & 4.5 & 0.045 & 0.011 & 0.047 & 3 & 0.141 & 0.033 & 0.0734 & 0.019 \\
\hline C3 & $\begin{array}{c}\text { Electrolytic } \\
\text { capacitor }\end{array}$ & 1 & $\begin{array}{l}2 \\
5\end{array}$ & $\begin{array}{l}2 \\
7\end{array}$ & 8 & $\begin{array}{c}0.051 \\
2\end{array}$ & 0.011 & 0.057 & 3 & 0.171 & 0.033 & 0.0529 & 0.013 \\
\hline
\end{tabular}




\begin{tabular}{|c|c|c|c|c|c|c|c|c|c|c|c|c|c|}
\hline $\mathrm{C} 4$ & $\begin{array}{l}\text { Electrolytic } \\
\text { capacitor }\end{array}$ & 1 & $\begin{array}{l}2 \\
5\end{array}$ & $\begin{array}{l}2 \\
7\end{array}$ & 9 & 0.563 & 0.011 & 0.057 & 3 & 0.171 & 0.033 & 0.073 & 0.167 \\
\hline $\mathrm{C} 5$ & $\begin{array}{l}\text { Electrolytic } \\
\text { capacitor }\end{array}$ & 1 & $\begin{array}{l}2 \\
5\end{array}$ & $\begin{array}{l}2 \\
7\end{array}$ & 8.5 & $\begin{array}{c}0.008 \\
5\end{array}$ & 0.011 & 0.057 & 3 & 0.171 & 0.033 & 0.8023 & 0.003 \\
\hline LED & $\begin{array}{l}\text { Light } \\
\text { emitting } \\
\text { diode }\end{array}$ & 1 & $\begin{array}{l}2 \\
5\end{array}$ & $\begin{array}{l}2 \\
7\end{array}$ & 2 & 0.005 & 0.034 & 0.35 & 0.2 & 0.07 & 0.0068 & 0.0121 & 0.046 \\
\hline $\mathrm{T}$ & Transformer & 1 & $\begin{array}{l}2 \\
5\end{array}$ & $\begin{array}{l}2 \\
7\end{array}$ & 210 & $\begin{array}{c}0.807 \\
7\end{array}$ & 0.003 & 0.047 & 1 & 0.047 & 0.03 & 0.0438 & 0.065 \\
\hline Q & $\begin{array}{c}\text { NPN } \\
\text { Transistor } \\
\text { (germaninu } \\
\text { m) }\end{array}$ & 1 & $\begin{array}{l}2 \\
5\end{array}$ & $\begin{array}{l}2 \\
7\end{array}$ & 39 & $\begin{array}{c}0.097 \\
5\end{array}$ & 0.072 & 4.3 & 0.2 & 0.86 & 0.0144 & 10.481 & 0.19 \\
\hline DZ1 & Zener Diode & 1 & $\begin{array}{l}2 \\
5\end{array}$ & $\begin{array}{l}2 \\
7\end{array}$ & 0.9 & $\begin{array}{c}0.002 \\
5\end{array}$ & 0.016 & 0.51 & 0.2 & 0.102 & 0.0032 & 0.029 & 0.001 \\
\hline DZ2 & Zener Diode & 1 & $\begin{array}{l}2 \\
5\end{array}$ & $\begin{array}{l}2 \\
7\end{array}$ & 4.8 & 0.012 & 0.016 & 0.51 & 0.2 & 0.102 & 0.0032 & 0.153 & 0.005 \\
\hline D1 & $\begin{array}{c}\text { General } \\
\text { Purpose } \\
\text { Diode } \\
\text { (germanium) }\end{array}$ & 1 & $\begin{array}{l}2 \\
5\end{array}$ & $\begin{array}{l}2 \\
7\end{array}$ & 2.4 & 0.006 & 0.0066 & 0.51 & 0.2 & 0.102 & 0.0032 & 0.077 & 0.0011 \\
\hline D2 & -do- & 1 & $\begin{array}{l}2 \\
5\end{array}$ & $\begin{array}{l}2 \\
7\end{array}$ & 15.5 & $\begin{array}{c}0.038 \\
8\end{array}$ & 0.0066 & 0.51 & 0.2 & 0.102 & 0.0032 & 0.495 & 0.007 \\
\hline D3 & -do- & 1 & $\begin{array}{l}2 \\
5 \\
\end{array}$ & $\begin{array}{l}2 \\
7 \\
\end{array}$ & 70.2 & $\begin{array}{c}0.175 \\
5\end{array}$ & 0.0066 & 0.51 & 0.2 & 0.102 & 0.0032 & 2.238 & 0.031 \\
\hline D4 & -do- & 1 & $\begin{array}{l}2 \\
5 \\
\end{array}$ & $\begin{array}{l}2 \\
7 \\
\end{array}$ & 5 & $\begin{array}{c}0.012 \\
5\end{array}$ & 0.0066 & 0.51 & 0.2 & 0.102 & 0.0032 & 0.159 & 0.002 \\
\hline R1 & $\begin{array}{l}\text { Film } \\
\text { Resistor }\end{array}$ & 1 & $\begin{array}{l}2 \\
5\end{array}$ & $\begin{array}{l}2 \\
7\end{array}$ & 0.8 & 0.8 & 0.0073 & 0.035 & 3 & 0.105 & 0.0219 & 0.7 & 0.158 \\
\hline $\mathrm{R} 2$ & -do- & 1 & $\begin{array}{l}2 \\
5\end{array}$ & $\begin{array}{l}2 \\
7\end{array}$ & 2 & 2 & 0.0073 & 0.035 & 3 & 0.105 & 0.0219 & 1.75 & 0.394 \\
\hline $\mathrm{R} 3$ & -do- & 1 & $\begin{array}{l}2 \\
5\end{array}$ & $\begin{array}{l}2 \\
7\end{array}$ & 0.05 & 0.05 & 0.0073 & 0.035 & 3 & 0.105 & 0.0219 & 0.044 & 0.01 \\
\hline $\mathrm{R} 4$ & -do- & 1 & $\begin{array}{l}2 \\
5\end{array}$ & $\begin{array}{l}2 \\
7 \\
\end{array}$ & 1.9 & 1.9 & 0.0073 & 0.035 & 3 & 0.105 & 0.0219 & 1.663 & 0.375 \\
\hline R5 & -do- & 1 & $\begin{array}{l}2 \\
5\end{array}$ & $\begin{array}{l}2 \\
7\end{array}$ & 6.1 & 6.1 & 0.0073 & 0.035 & 3 & 0.105 & 0.0219 & 5.338 & 1.202 \\
\hline R6 & -do- & 1 & $\begin{array}{l}2 \\
5 \\
\end{array}$ & $\begin{array}{l}2 \\
7 \\
\end{array}$ & 0.14 & 0.14 & 0.0073 & 0.035 & 3 & 0.105 & 0.0219 & 0.123 & 0.028 \\
\hline & & & & & & & & & & & Total & $25.26 \times 10^{-6} \mathrm{hr}$ & $3.1461 \times 10^{-6} / \mathrm{hr}$ \\
\hline
\end{tabular}

Where,

$\lambda_{\mathrm{BN}}=$ Base failure rate of phone charger in Nigeria

$\lambda_{\mathrm{BD}}=$ Base failure rate of the charger in the designed environment

$\mathrm{T}^{0}(\mathrm{D})=$ Average room temperature of the designed environment

$\mathrm{T}^{0}(\mathrm{~N})=$ Average room temperature of Nigeria

$\mathrm{K}=$ Voltage stress ratio

$\lambda_{\text {effD }}=$ Effective base failure rate for designed environment

$\lambda_{\text {effN }}=$ effective base failure rate for the applied environment (Nigeria)

Reliability can be assessed from the failure rates obtained from table 1 for china and the applied environment (Nigeria) as $\lambda_{\text {effD }}$ and $\lambda_{\text {effN }}$ respectively. Reliability assessments are obtained using equation 2.10 for the period of five years as shown in table 2 and 3 .

Table 2: Reliability Result

\begin{tabular}{|c|c|c|c|c|c|}
\hline \multirow{3}{*}{ China } & Year 1 & Year 2 & Year 3 & Year 4 & Year 5 \\
& 0.9780 & 0.9464 & 0.9206 & 0.8956 & 0.8713 \\
\hline
\end{tabular}

\begin{tabular}{|l|l|l|l|l|l|}
\hline Nigeria & 0.8015 & 0.6424 & 0.5146 & 0.4127 & 0.3308 \\
\hline
\end{tabular}


Table 3: Percentage of Reliability

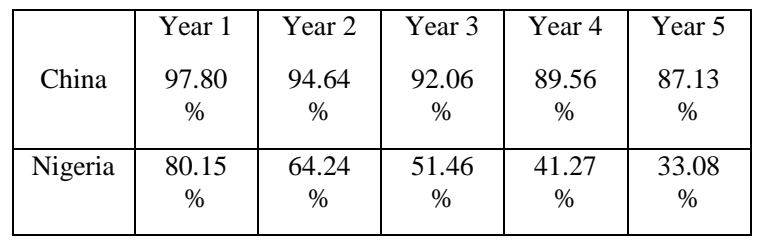

Example, for one year-365 days x 24 hours $=8760 \mathrm{hrs}$

$\mathrm{R}=e^{-(31461 \mathrm{E}-6 \times 8760)}=97.28 \%$

The reliability result taken over five years for the two environments were plotted against time to realize the graph in Fig 3.

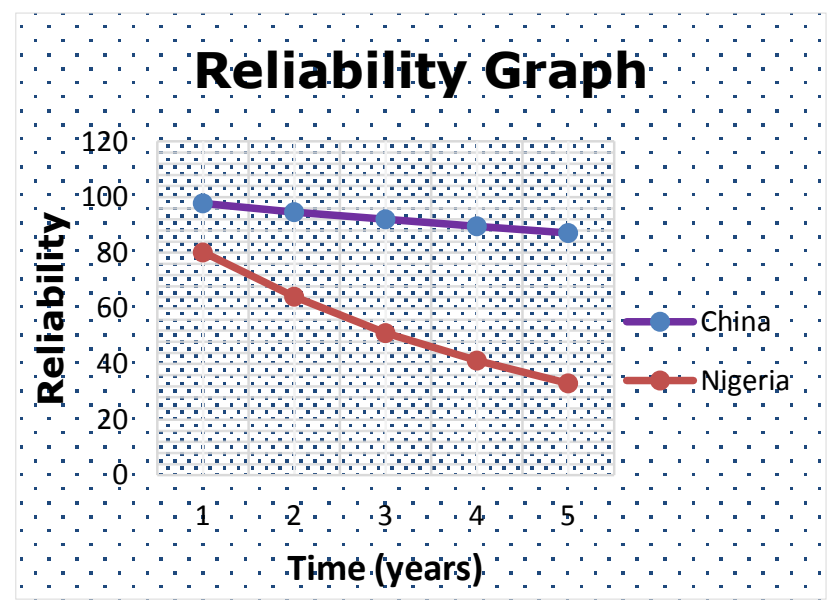

Fig. 3: Reliability Graph

\section{DISCUSSION OF RESULTS}

From Fig.3, we can appreciate and compare the reliability of the country for which the system was designed for and that of Nigeria and from it we see that the charger under consideration has a relatively higher reliability in the designed country (China) than the applied environment (Nigeria). The exponentially decaying reliability function graph above shows that the system has a higher failure rate in Nigeria, due to factors, which are associated with the environment like voltage fluctuation, surge frequency, high relative humidity, among others. The ratio of the failure rate of Nigeria to China is $8: 1$.

Comparatively, the rate of failure of the charger in the designed country is very much less than the Nigerian case. From the failure rate of the system obtained for the two environments, we obtain the mean time to failure (MTTF) of the system can be obtained as follows

$$
\begin{aligned}
& \text { MTTF }=\frac{1}{\lambda_{\text {effD }}} \\
& \text { MTTF }_{c}=\frac{1}{3.1461 \times 10^{-6}} \times \frac{1}{8760}=36.3 \mathrm{yrs} \\
& \text { MTTF }_{\mathrm{N}}=\frac{1}{24.1461 \times 10^{-6}}=\frac{1}{8760}=4.5 \mathrm{yrs}
\end{aligned}
$$

The mean time the system is expected to function before failure (MTTF) in Nigeria is 4.5 years as against 36.3 years for the designed country. The rate is about eight times higher than the Nigerian case.

\section{CONCLUSION AND RECOMMENDATIONS}

The comparative results for the system at hand, taken over five years between the country for which the system was designed for and that of Nigeria, showed that lower reliability is associated with the use of the system in Nigeria than the designed country (China)

The following steps are recommended for the reliability of the charger to be higher in Nigeria:

a. There should be provision of parallel configuration in the design so as to reduce the rate of failure of the components in the system.

b. The design of the charger should consider the environmental as well as stress factors in Nigeria

\section{ACKNOWLEDGMENTS}

We are grateful to our wives and families for their encouragements and supports towards the realization of this piece of work. We did not forget our devoted colleagues in the Department of Electrical and Electronics Engineering.

\section{REFERENCES}

[1] Abdullahi, M.I., Akinsanmi, O., Muazu, M,B., and Jibril, Y. (2007) "Reliability Assessment of an Electronic System: A Case Study of a British Siren in Nigeria." Journal of Applied Sciences Research, Vol. 3 (12): 1671 1675, Pakistan.

[2] Akinsanmi, O., Ekundayo, K.R., and Okorie, P.U. (2013) "Reliability Assessment of an Electronic System: A Case Study of Nokia N1600 Mobile Phone Cahrger in Zaria, Nigeria." Journal of Advanced Material Research, Vol. 824, PP. 170-177

[3] Akinsanmi, O. (2003) "Reliability Assessment of UPS systems in Developing Countries. Unpublished M.Sc. Eng. Thesis, A.B.U, Zaria

[4] Akinsanmi, O. (2005) "Assessing the Reliability of a Nokia 3310 chargers" Samaru Journal of Information studies, Vol. 5, PP 40 - 47, Department of Library Science, Ahmadu Bello University, Zaria.

[5] Akinsanmi, O. (2009) "Assessing the Reliability of a Universal Mobile Charger in Nigeria." Journal of Applied Science Research, Pakistan, Vol. (12).

[6] Andrew. C. P, Jordan, V. C. and Lawrence, R.P (1995). "Management for Engineers "John Wiley and sons, England, Pp. 328- 338.

[7] Arsenault. J.E., 1980 "Reliability and Maintainability of Electronics systems" Pitman Ltd, United Kingdom. PP 162-187.

[8] Oroge, C. A (1991) Fundamental of Reliability and Testing Methods; Sooji Press Ltd, Kaduna, Nigeria.

[9] Taylor P. F. U (1989) Reliability Assessment and Design of Micro Computers for Administrative Purposes in Developing Countries PhD. Thesis, ABU, Zaria.

[10] United States (USA) Military Handbook 217: Generic Failure Rate Tables for Micro Electronic Components 